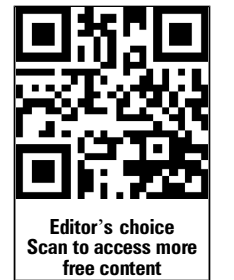

- Additional material is published online only. To view please visit the journal online (http://dx.doi.org/10.1136/ heartjnl-2013-304888).

${ }^{1}$ Erasmus Medical Center, Rotterdam, The Netherlands ${ }^{2}$ Norfolk \& Norwich University NHS Hospital, Norwich, UK ${ }^{3}$ Hospital de Sant Pau, Barcelona, Spain

${ }^{4}$ Milton S. Hershey Medical Center, Hershey, Pennsylvania, USA

${ }^{5}$ Oslo University Hospital, Rikshospitalet, Oslo, Norway

${ }^{6}$ Regional Hospital of Bolzano, Bolzano, Italy

${ }^{7}$ Policlinico San Donato IRCCS, Milano, Italy

${ }^{8}$ University of Washington, Seattle, Washington, USA

${ }^{9}$ Ghent University Hospital, Ghent, Belgium

${ }^{10}$ Imperial College London, Chelsea and Westminster Hospital, London, UK

${ }^{11}$ University of Groningen, University Medical Center Groningen, Groningen, The Netherlands

\section{Correspondence to}

Dr P G Pieper, Department of Cardiology, University Medical Centre Groningen, University of Groningen, PO Box 30.001, Groningen 9700 RB, The Netherlands;

p.g.pieper@umcg.nl

Received 4 September 2013 Revised 2 October 2013 Accepted 3 October 2013 Published Online First 29 November 2013

\section{SLinked}

- http://dx.doi.org/10.1136/ heartjnl-2013-304986

To cite: Ruys TPE, Roos-Hesselink JW, Hall R, et al. Heart 2014;100: 231-238.

\title{
Heart failure in pregnant women with cardiac disease: data from the ROPAC
}

\author{
Titia P E Ruys, ${ }^{1}$ Jolien W Roos-Hesselink, ${ }^{1}$ Roger Hall, ${ }^{2}$ Maria T Subirana-Domènech, ${ }^{3}$ \\ Jennifer Grando-Ting, ${ }^{4}$ Mette Estensen, ${ }^{5}$ Roberto Crepaz, ${ }^{6}$ Vlasta Fesslova, ${ }^{7}$ \\ Michelle Gurvitz, ${ }^{8}$ Julie De Backer, ${ }^{9}$ Mark R Johnson, ${ }^{10}$ Petronella G Pieper ${ }^{11}$
}

\begin{abstract}
Objective Heart failure (HF) is one of the most important complications in pregnant women with heart disease, causing maternal and fetal mortality and morbidity.
\end{abstract}

Methods This is an international observational registry of patients with structural heart disease during pregnancy. Sixty hospitals in 28 countries enrolled 1321 women between 2007 and 2011. Pregnant women with valvular heart disease, congenital heart disease, ischaemic heart disease, or cardiomyopathy could be included. Main outcome measures were onset and predictors of $\mathrm{HF}$ and maternal and fetal death.

Results In total, $173(13.1 \%)$ of the 1321 patients developed HF, making HF the most common major cardiovascular complication during pregnancy. Baseline parameters associated with HF were New York Heart Association class $\geq 3$, signs of HF, WHO category $\geq 3$, cardiomyopathy or pulmonary hypertension. HF occurred at a median time of 31 weeks gestation (IQR 23-40) with the highest incidence at the end of the second trimester (34\%) or peripartum (31\%). Maternal mortality was higher in patients with $\mathrm{HF}(4.8 \%$ in patients with $\mathrm{HF}$ and $0.5 \%$ in those without $\mathrm{HF} p<0.001)$.

Pre-eclampsia was strongly related to HF (OR 7.1, 95\% $\mathrm{Cl} 3.9$ to 13.2, p<0.001). Fetal death and the incidence of preterm birth were higher in women with $\mathrm{HF}$ compared to women without HF $(4.6 \%$ vs $1.2 \%$, $p=0.001$; and $30 \%$ vs $13 \%, p=0.001$ ).

Conclusions HF was the most common complication during pregnancy, and occurred typically at the end of the second trimester, or after birth. It was most common in women with cardiomyopathy or pulmonary hypertension and was strongly associated with pre-eclampsia and an adverse maternal and perinatal outcome.

\section{OBJECTIVES}

Pregnancy may be considered as a physiological stress test, revealing latent medical conditions such as hypertension and diabetes. ${ }^{1}$ This is particularly true for women with underlying heart disease, where pregnancy may cause a deterioration of a known heart condition or precipitate the presentation of an undiagnosed heart problem. ${ }^{1}$ During pregnancy, cardiac output increases by $30-50 \%$, where increase in plasma volume leads to increase in stroke volume and heart rate. ${ }^{2}$ The increase in cardiac workload may precipitate heart failure
(HF), ${ }^{3-5}$ which is associated with significant maternal and fetal morbidity and mortality. ${ }^{6}$

Despite the poor prognosis associated with the diagnosis of HF during pregnancy, there is very little information in the literature on the subject. The onset of HF during pregnancy may differ according to the underlying heart disease, and may be related to the physiological changes during pregnancy, but data in the literature are scarce. Peripartum cardiomyopathy is a pregnancy-specific type of cardiomyopathy, where HF by definition occurs towards the end of pregnancy or in the months following delivery. ${ }^{7}$ In pregnant women with valvular heart disease (VHD), HF has been described both during pregnancy and after delivery. ${ }^{8-10}$ Labour and delivery are considered a particularly high-risk period because of cardiac stress and changes in cardiac output caused by pain, anxiety and exertion, uterine contractions, bleeding, anaesthesia, autotransfusion from the involuting uterus, and resorption of oedema. ${ }^{6-13}$

In pregnant women with underlying heart disease, the risk of developing complications depends on the type and severity of cardiac disease. ${ }^{2} 59$ 14-19 Large cohort studies have focused on prediction of a composite endpoint of cardiac events (arrhythmia, HF and other cardiovascular complications). ${ }^{2-4}$ This approach fails to distinguish between the relatively easily managed complications, such as most supraventricular arrhythmias, and the more severe complications, such as HF. Therefore, in this study, we focus on HF during pregnancy. We have investigated the timing of the diagnosis of HF, its associations and the factors which predict its occurrence in a large cohort of pregnant women with structural or ischaemic heart disease (IHD).

\section{METHODS}

\section{Study design}

The Registry On Pregnancy And Cardiac disease (ROPAC) was established in 2007 (see online appendix for more information). Sixty hospitals in 28 countries enrolled 1321 pregnant women with structural heart disease (valvular or congenital heart disease (CHD) or cardiomyopathy) or IHD. Enrolled patients underwent pregnancy sometime between 2007 and June 2011.

\section{Data}

The study protocol with definitions and the first results of this registry were published previously. ${ }^{19}$ 
HF was defined in these patients with various underlying heart diseases, according to ACC/AHA guidelines, as a clinical syndrome that is characterised by specific symptoms (dyspnea and fatigue) in the medical history and signs (of fluid retention, such as oedema, rales) on the physical examination as judged by the treating cardiologist. ${ }^{20}$ The HF episode was only registered when signs or symptoms of HF were present which required new treatment, change of treatment or hospital admission. Pulmonary hypertension was judged as such by the including cardiologist. Countries were divided into developed or developing according to the International Monetary Fund Classification. ${ }^{21}$ Other definitions have been described in the overview paper which has been previously published. ${ }^{19}$ Onset of $\mathrm{HF}$ in terms of gestational age was calculated using the expected term date. When a patient developed HF after delivery, we described the timing as the number of weeks after delivery. In patients with HF during and postpregnancy, only the first manifestation of HF was used to compute the time of HF. For the calculation of median time of HF per diagnosis, we added the number of weeks after delivery to 40 weeks when HF occurred after delivery. For example, HF occurring 6 weeks after delivery in a woman delivered at 38 weeks is calculated as $\mathrm{HF}$ at 46 weeks.

We stratified the patients into four risk groups using a modified WHO risk classification for pregnant women with cardiac disease. Dependent on diagnosis and severity of disease, risk classification ranges from class I (low risk), to class IV (contraindication for pregnancy). ${ }^{5} 22 \mathrm{CHD}$ patients were further classified by complexity of heart disease, according to a generally accepted classification. ${ }^{23}$ Diseases that were not accounted for in this classification were scored by two authors (TPER and PGP). Additionally, the type of heart lesion was classified into leftsided lesions (such as aortic valve disease, mitral valve disease and most cardiomyopathies), right-sided lesions (such as Ebstein's anomaly, tetralogy of Fallot, pulmonary stenosis) and shunt lesions (such as atrial or ventricular septal defects).

The primary study end point was HF, and secondary study endpoints included: birth weight, fetal death (defined as fetal death after 22 weeks of pregnancy or birth weight $500 \mathrm{~g}$ ), neonatal death, low birth weight $(<2500 \mathrm{~g})$, premature birth ( $<37$ weeks of gestation) or Apgar score $<7$. Other complications collected included symptomatic supraventricular tachycardia (either paroxysmal or permanent), symptomatic ventricular arrhythmias (excluding ventricular extra beats), thromboembolic complications (including mechanical valve thrombosis, venous thromboembolism and cerebrovascular event) and bleeding complications (requiring transfusion). This study focuses on HF. Data on follow-up was complete in $96 \%$ of patients. More detailed information on maternal and fetal outcome, in general, can be found in the overview article. ${ }^{19}$

\section{Statistical methods}

Categorical data are presented as frequencies (numbers) and percentages. One-sample Kolmogorov-Smirnov tests and histograms were used to check normality of continuous data. Normally distributed continuous data are presented as mean values \pm one $S D$, whereas data which were not normally distributed were presented as medians with IQR. Differences in categorical data between independent patient groups were compared by $\chi^{2}$ tests. Fisher's exact tests were applied if any expected cell count was less than five. Differences in continuous data between independent patient groups were compared by Student $t$ tests. Adjusted birth weight was calculated using a linear regression, and was adjusted for gestational age, smoking, fetal sex, maternal age, diabetes and pre-eclampsia. Univariable logistic regression analysis was performed to identify baseline patient characteristics (before pregnancy) associated with HF. The following baseline variables were assessed: $\mathrm{CHD}, \mathrm{VHD}$, cardiomyopathy, IHD, right-sided lesion, left-sided lesion, shunt lesion, NYHA (New York Heart Association) class $\geq 3$, modified WHO class $\geq 3$, atrial fibrillation (either paroxysmal or permanent), nulliparity, hypertension (hypertension (systolic $>140 \mathrm{~mm} \mathrm{Hg}$ or diastolic $>90 \mathrm{~mm} \mathrm{Hg}$ before pregnancy or the use of antihypertensive treatment), smoking (before and during pregnancy), developing versus developed countries (according to International Monetary Fund classification), signs of HF, pulmonary hypertension, mechanical valves and the use of any medication before pregnancy. Echocardiographic data (fractional shortening $<30 \%$ or systolic ventricular function (qualitatively scored with eyeballing) normal/moderate/severely impaired: systemic or pulmonary) were used only in the univariable regression, since adequate data were only available in 259 patients. Parameters developing during pregnancy, such as diabetes and pre-eclampsia were not taken into account in this univariable and multivariable analysis, since the goal was to construct a prepregnancy risk model. We excluded patients with a first manifestation of peripartum cardiomyopathy in the current pregnancy for the univariable and multivariable analysis only, since we intended to predict the occurrence of HF from baseline data in women with known structural or IHD, while women with a first manifestation of peripartum cardiomyopathy were by definition healthy at baseline. Variables that were associated with an increased incidence of the studied endpoints $(p<0.15)$ entered the multivariable analysis. Unless specified otherwise, $p$ values $<0.05$ (2-sided test) were considered statistically significant. All statistical analyses were performed using SPSS V.20.0 (SPSS, Chicago, USA).

\section{RESULTS}

\section{Baseline characteristics}

Of the 1321 enrolled patients, 173 (13.1\%) developed HF during pregnancy or after delivery, including 16 cases of HF during delivery not included in the previous publication. ${ }^{19}$ Baseline characteristics of patients with and without HF are shown in table 1 . There was a significant difference in type of lesion $(\mathrm{p}<0.001)$, with more women with HF having left-sided lesions (68\% vs $45 \%)$. By contrast, fewer women with HF had a right-sided lesion $(12 \%$ vs $27 \%$ ) or a shunt lesion (20\% vs $27 \%$ ). Of all shunt lesions $35 \%$ of patient had uncorrected shunts and 10\% of patients had some degree of pulmonary hypertension. Different diagnoses are displayed in figure 1. In total, 71 patients with HF had CHD, 64 had VHD and 36 had CMP. In patients with available echocardiographic data, patients with HF had a lower mean fractional shortening at baseline than patients without HF $(31 \%$ vs $36 \%$ p $=0.007)$.

\section{Predictors of $\mathrm{HF}$}

The results of the univariable and multivariable logistic regression are shown in table 2. Independent baseline parameters associated with HF were NYHA class $\geq 3$ and signs of HF prior to pregnancy, WHO category $\geq 3$, cardiomyopathy or pulmonary hypertension. During pregnancy, a diagnosis of preeclampsia was related to the occurrence of HF with an OR of $7.1(95 \%$ CI 3.9 to $13.2 \mathrm{p}<0.001)$. Of all patients in the registry who developed pre-eclampsia, 30\% developed HF as well. Of patients with pre-eclampsia and HF, 29\% had peripartum cardiomyopathy, 29\% mitral valve disease, 14\% other cardiomyopathies and $14 \%$ an ASD. In the univariable analysis, CHD was associated with a lower risk of $\mathrm{HF}$ than other diagnoses 
Table 1 Baseline characteristics of patient with and without HF

\begin{tabular}{|c|c|c|c|c|}
\hline \multirow{2}{*}{$\begin{array}{l}\text { Patient without HF } \\
n=1148\end{array}$} & \multirow{2}{*}{$\begin{array}{l}\text { Total } \\
\text { group } \\
\text { p Value }\end{array}$} & \multirow[t]{2}{*}{$n=1321$} & \multirow[t]{2}{*}{$\begin{array}{c}\text { Patient } \\
\text { with HF } \\
n=173\end{array}$} & \\
\hline & & & & \\
\hline Mean age in years (SD) & $30(5.6)$ & $29(6.2)$ & $30(5.6)$ & 0.18 \\
\hline Nulliparity (\%) & 50 & 42 & 51 & 0.021 \\
\hline Atrial fibrillation (\%) & 2 & 6.4 & 1.3 & $<0.001$ \\
\hline Hypertension & 6.7 & 8.1 & 6.5 & 0.45 \\
\hline Smoking (\%) & 3.3 & 4 & 3.1 & 0.53 \\
\hline $\begin{array}{l}\text { Any medication before pregnancy } \\
(\%)\end{array}$ & 28 & 36 & 27 & 0.01 \\
\hline NYHA class (\%) & & & & $<0.001$ \\
\hline NYHA class 1 & 70 & 36 & 76 & \\
\hline NYHA class 2 & 25 & 48 & 21 & \\
\hline NYHA class 3 & 3.1 & 15 & 1.3 & \\
\hline NYHA class 4 & 0.3 & 1.2 & 0.2 & \\
\hline WHO category (\%) & & & & $<0.001$ \\
\hline WHO 1 & 18 & 1.8 & 21 & \\
\hline WHO 2 & 39 & 19 & 42 & \\
\hline WHO 3 & 38 & 60 & 35 & \\
\hline WHO 4 & 4 & 19 & 1.9 & \\
\hline Type of lesion (\%) & & & & $<0.001$ \\
\hline Left sided lesions & & 68 & 45 & \\
\hline Right sided lesions & & 12 & 27 & \\
\hline Shunt lesions & & 20 & 27 & \\
\hline Type of heart disease (\%) & & & & $<0.001$ \\
\hline Valvular heart disease & 25 & 37 & 24 & \\
\hline Cardiomyopathy & 6.7 & 21 & 4.5 & \\
\hline Ischaemic heart disease (\%) & 1.9 & 1.2 & 2 & \\
\hline CHD (\%) & 66 & 41 & 70 & \\
\hline Complexity of CHD & & & & 0.24 \\
\hline Simple CHD (\%) & 35 & 35 & 26 & \\
\hline Moderate complex CHD (\%) & 52 & 52 & 57 & \\
\hline Complex CHD (\%) & 13 & 13 & 17 & \\
\hline
\end{tabular}

with an OR of 0.3 (95\% CI 0.2 to 0.4 ). When corrected for other univariable predictors of $\mathrm{HF}$ in a multivariable model, this was still significant with an OR of 0.40 (95\% CI 0.23 to $0.62 \mathrm{p}<0.001)$. Uncorrected shunts were not a significant predictor in neither univariable nor multivariable analysis. HF occurred more often in patients with shunt lesions who had pulmonary hypertension ( $7 \%$ vs $41 \% \mathrm{p}<0.001)$. Concomitant valvular disease did not contribute to HF in patients with shunt lesion. Of patients with persistent duct, 23\% had HF, these were mainly patients with pulmonary hypertension, or an uncorrected shunt or concomitant valvular disease. In patients with mitral stenosis and/or mitral regurgitation HF occurred relatively often (table 3); 35\% of these patients had pulmonary hypertension.

\section{Onset of HF}

Median onset of HF was at 31 weeks of gestation (IQR 23-40). Of all patients with HF, 106 (61\%) had HF only during pregnancy, 40 (23\%) only after delivery and 27 (16\%) during pregnancy and after delivery. HF occurred in $7 \%$ in the first trimester, 34\% occurred in the second trimester, $28 \%$ in the third trimester, $10 \%$ at delivery and $21 \%$ postpartum. More detailed timing of $\mathrm{HF}$ is displayed in figure 2. There is a peak in weeks $23-30$ of gestation, and in the first weeks after delivery. Of the 20 patients with postpartum HF, $61 \%$ occurred in the first week after delivery; in 11 of these patients $(55 \%)$, HF occurred in the first $24 \mathrm{~h}$ after delivery. Postpartum HF was encountered in peripartum cardiomyopathy (21\%), mitral regurgitation (14\%), other cardiomyopathies $(10.5 \%)$ and Tetralogy of Fallot (6\%). There were large differences in frequency and timing of HF in different patient groups (table 3). HF was common in patients with a cardiomyopathy, and occurred mainly in the weeks around delivery. In VHD, patients HF occurred throughout pregnancy. In patients with shunt lesions, HF typically occurred around 25 weeks of gestation and was more common in patients with pulmonary arterial hypertension. Patients with pulmonary hypertension had HF at a mean of 29 weeks of gestation, whereas patients without pulmonary hypertension had $\mathrm{HF}$ at a mean of 31 weeks of gestation $(p=0.33)$.

\section{Maternal and fetal outcome}

The diagnosis of HF was associated with a significantly higher maternal mortality $(p<0.001)$. In all but one of the patients who did not survive, the reason of death was cardiac failure, either acute of chronic. The patient who did not have a cardiac reason, died of bronchopneumonia. Obstetric complications were also more common in these patients, as shown in table 4. Mode of delivery in patients with HF, was by emergency caesarean section in $22 \%$, by elective caesarean section in $36 \%$ and vaginally in $40 \%$; in $3 \%$, mode of delivery was not recorded. Overall, $58 \%$ of patients with HF were delivered by caesarean section compared to $38 \%$ in patients without HF $(\mathrm{p}<0.001)$. Caesarean section was for cardiac reasons in $57 \%$ of all HF patients with a caesarean section, versus $29 \%$ in patients without HF $(\mathrm{p}<0.001)$.

Fetal death occurred more often in patients with HF $(p=0.001)$. Birth weight was lower than $2500 \mathrm{~g}$ in $24 \%$ of patients with $\mathrm{HF}$, and in $13 \%$ in patients without $\mathrm{HF}$ $(\mathrm{p}<0.001)$. Of these children, $33(80 \%)$ were born prematurely. Median time of delivery was 38 weeks (IQR 36-39) for patients with HF, and 39 weeks (IQR 37-40) in patients without HF $(\mathrm{p}<0.001)$. There was no correlation between onset of HF and timing of delivery $\left(\mathrm{R}^{2}=0.003\right)$ nor was there a correlation $\left(\mathrm{R}^{2}=0.023\right)$ between onset of HF and birth weight (corrected for time of delivery).

\section{DISCUSSION}

In this large worldwide registry of pregnant women with underlying cardiac disease, ${ }^{19}$ we investigated timing and predictors of HF. HF was the most common complication, occurring in $13 \%$ of the patients. ${ }^{19}$ We showed that the onset of HF depended on the underlying cardiac diagnosis, with HF most frequently diagnosed in the second or third trimester, or shortly after delivery. HF was found most often in women with poor prepregnancy cardiac function, with a diagnosis of cardiomyopathy or pulmonary hypertension. Patients with HF had a higher rate of adverse maternal and fetal outcomes. Furthermore, this is the first study to identify specific predictors for the occurrence of $\mathrm{HF}$.

Rate of HF in relation to different underlying cardiac diagnoses In this registry, the rates of $\mathrm{HF}$ in various diagnoses slightly differ from reported rates in the literature. For simple diagnoses, such as mitral regurgitation, aortic coarctation, aortic abnormalities and shunt lesions, rates of HF are high in this registry when compared to the literature. $^{24} 25$ This may be partially explained by the high percentage of pulmonary hypertension in some of the lesions, such as mitral stenosis and/or regurgitation and uncorrected shunt lesions. Yap et $a l^{26} 27$ described a higher rate 

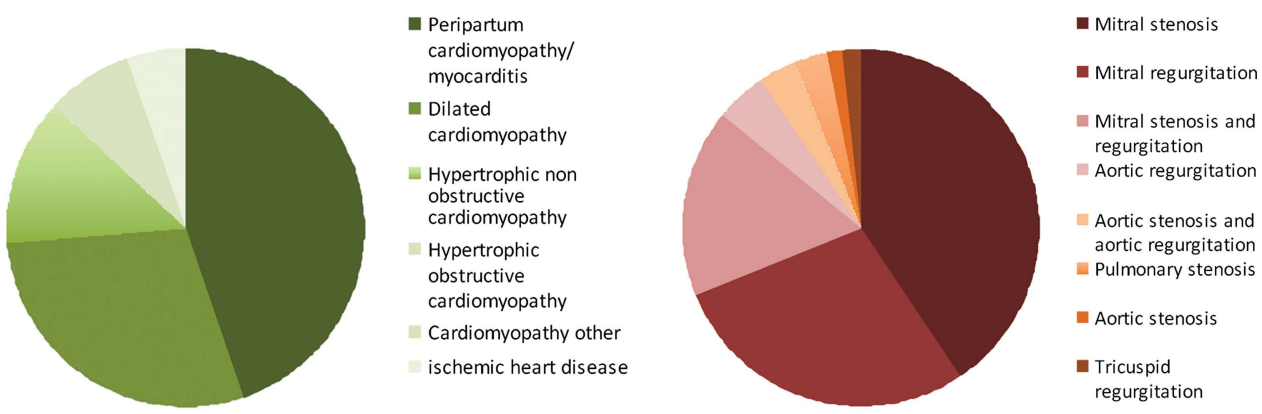

Figure 1 Diagnosis in patients with heart failure. In green shades, cardiomyopathy ( $n=36)$; in red shades, valvular heart disease ( $n=64)$; in other shades, congenital heart disease $(n=71)$.

of complications in patients with uncorrected shunts, in patients with atrial septal defects and ventricular septal defect, but none of the women developed HF. We reported a HF rate of $3.8 \%$ in patients with atrial switch procedure for transposition of the great arteries which is relatively low compared to previously reported rates of $2.7 \%, 4.1 \%$ and $7.1 \% .^{28-30}$

\section{Predictors}

In our univariable analysis, several factors were associated with an increased or low risk of HF (table 2). The factors cardiomyopathy, NYHA class $\geq 3$, WHO $\geq 3$, pre-pregnancy HF and pulmonary hypertension remained significantly associated in the multivariate analysis. The presence of a left-sided lesion and medication use prior to pregnancy showed a weak association. The loss of several of the factors of the univariable analysis suggests that their risk was indirectly mediated through a second factor. For example, the relationship of HF with developing countries was probably due to more severe disease, including a higher prevalence of pulmonary hypertension. Of those factors that remained significant, the strongest were prepregnancy HF and poor functional class and, in addition, high risk of pregnancy as represented by high WHO class. These are useful parameters in counselling of women with heart disease considering pregnancy. Interestingly, WHO class was a predictor of HF in the multivariable analysis, even though this classification was designed to predict the risk of any cardiovascular complication and not just of HF. In the prospective study of Siu et al, $\mathrm{EF}<40 \%$ predicted complications. We found that $\mathrm{EF}$ and fractional shortening were strong univariable predictors of $\mathrm{HF}$ in the subgroup of patients in which these data were available, however, these variables could not be tested in the multivariable model due to missing data. Pulmonary hypertension has also been recognised as a high-risk condition and predictor for cardiovascular events in previous studies, ${ }^{31}{ }^{32}$ However, pulmonary hypertension did not predict complications in the studies of Drenthen et al and Siu et al, probably because few patients with pulmonary hypertension were included in their studies. ${ }^{34}$ In this registry, we included patients from developing countries where the prevalence of pulmonary hypertension is relatively high, therefore, we could identify pulmonary hypertension as a predictor of HF.

In our series, the presence of a mechanical valve was not a predictor of $\mathrm{HF}$, but these patients are mainly at risk for other complications, such as haemorrhage and valve thrombosis. Similarly, IHD was not a predictor of HF, possibly because left ventricular function may have been almost normal in most of these patients. The number of IHD patients was very small and more data are needed to draw conclusions regarding this patient group. Patients with $\mathrm{CHD}$ had a lower risk than patients with VHD, IHD or cardiomyopathy, but compared with the rate of $\mathrm{HF}$ in the normal healthy population, this risk is still increased. Patients with right-sided lesions and cyanotic lesions (mostly corrected) had a lower risk than patients with left-sided lesions.

Biomarkers, such as B-type natriuretic peptide (BNP), are established markers of $\mathrm{HF}^{33}$ However, their role during pregnancy in women with heart disease is incompletely studied. In the study by Tanous et al. ${ }^{34}$ BNP levels were associated with cardiovascular events during pregnancy. Importantly, BNP levels lower than $100 \mathrm{pg} / \mathrm{mL}$ had a negative predictive value of $100 \%$ for identifying events during pregnancy. However, since in a large proportion of patients the BNP level was only measured at time of the event and not before this, additional studies are clearly warranted to show the value of BNP in prepregnancy risk models. In this registry, we did not collect data on biomarkers.

\section{Timing}

To date, data on the timing of HF in pregnant women with heart disease are scarce. The peripartum period is regarded as 
Table 2 Predictors of HF

\begin{tabular}{|c|c|c|c|}
\hline Univariable & OR & $95 \% \mathrm{Cl}$ & p Value \\
\hline Congenital heart disease & 0.3 & (0.2 to 0.4$)$ & $<0.001$ \\
\hline Valvular heart disease & 1.9 & (1.4 to 2.7 ) & $<0.001$ \\
\hline Cardiomyopathy & 4.8 & (3.0 to 7.88 ) & $<0.001$ \\
\hline Ischaemic heart disease & 0.6 & (0.1 to 2.4 ) & 0.45 \\
\hline Right-sided lesion & 0.4 & (0.2 to 0.6$)$ & $<0.001$ \\
\hline Left-sided lesion & 2.7 & (1.9 to 3.8$)$ & $<0.001$ \\
\hline Shunt lesion & 0.7 & $(0.5$ to 1.0$)$ & 0.08 \\
\hline Cyanotic lesion & 0.4 & (0.2 to 0.6$)$ & $<0.001$ \\
\hline NYHA class $\geq 3$ & 6.2 & (3.7 to 10.5 ) & $<0.001$ \\
\hline WHO $\geq 3$ & 5.3 & (3.7 to 7.6 ) & $<0.001$ \\
\hline Nulliparity & 0.7 & (0.5 to 0.9 ) & 0.02 \\
\hline Hypertension & 1.3 & (0.7 to 2.3 ) & 0.45 \\
\hline Smoking & 1.3 & (0.6 to 3.0$)$ & 0.53 \\
\hline Developing countries & 3.2 & (2.2 to 4.6$)$ & $<0.001$ \\
\hline Signs of HF prior to pregnancy & 17.3 & (11.6 to 25.7$)$ & $<0.001$ \\
\hline Rhythm: atrial fibrillation before pregnancy & 5.1 & (2.3 to 11.4 ) & $<0.001$ \\
\hline Pulmonary hypertension & 4.5 & (3.1 to 6.6$)$ & $<0.001$ \\
\hline Mechanical valves & 0.5 & (0.2 to 1.5$)$ & 0.25 \\
\hline Any medication before pregnancy & 1.6 & (1.1 to 2.2$)$ & 0.011 \\
\hline Echo prior to pregnancy: systemic ventricular function moderate/ severely impaired & 4.2 & (1.7 to 10.3$)$ & 0.002 \\
\hline $\mathrm{FS}<30$ & 3.4 & (1.3 to 8.9$)$ & 0.02 \\
\hline Pulmonary ventricular function moderate/severely impaired & 3.1 & (0.9 to 10.5$)$ & 0.07 \\
\hline \multicolumn{4}{|l|}{ Multivariable } \\
\hline Valvular heart disease & 1.0 & $(0.5$ to 1.7$)$ & 0.88 \\
\hline Cardiomyopathy & 4.6 & (2.3 to 9.1 ) & $<0.001$ \\
\hline Developing countries & 0.9 & (0.5 to 1.6$)$ & 0.77 \\
\hline NYHA class $\geq 3$ & 2.3 & (1.2 to 4.4$)$ & 0.01 \\
\hline WHO $\geq 3$ & 2.3 & (1.5 to 3.6$)$ & $<0.001$ \\
\hline Any medication before pregnancy & 0.8 & (0.4 to 1.0$)$ & 0.08 \\
\hline Rhythm: atrial fibrillation before pregnancy & 2.4 & (0.8 to 6.9$)$ & 0.11 \\
\hline Signs of HF prior to pregnancy & 9.6 & (5.9 to 15.5 ) & $<0.001$ \\
\hline Pulmonary hypertension & 1.8 & $(1.0$ to 3.0$)$ & 0.04 \\
\hline Left-sided lesion & 1.6 & (1.0 to 2.7$)$ & 0.07 \\
\hline
\end{tabular}

HF, heart failure; NYHA, New York Heart Association.

high-risk period because of cardiac stress due to pain and anxiety as well as fluid overload. ${ }^{11}$ While peripartum cardiomyopathy by definition occurs in the months around delivery, patients with VHD are reported to present with HF during pregnancy as well as in the peripartum period. ${ }^{7}-^{10}$ In our study, there appeared to be two peaks, one at the end of the second and beginning of the third trimester, and the other around delivery. Within this pattern, there were distinct clusters of diagnostic groups. Women with abnormalities causing pulmonary hypertension, such as shunt lesions and mitral stenosis, typically went into HF before 30 weeks gestation. In those with most forms of cardiomyopathy, HF was diagnosed peripartum. The first peak, corresponding to 23-30 weeks occurred when most of the important haemodynamic changes had taken place. Stroke volume then has reached its maximum (up to $130 \%$ of normal) for a number of weeks, but heart rate is just starting to increase. The second peak occurred around delivery, corresponding with peripartum haemodynamic changes. Peripartum cardiac output increases with an additional $25 \%$, and after delivery, autotransfusion from the uterus will further increase circulatory volume thereby stressing both the left and RV. Firm conclusions for all diagnostic groups cannot be made, some of the diagnostic groups were small.

\section{Pregnancy outcome in patients with HF}

Pre-eclampsia during pregnancy was associated with HF with an OR of 7.1. In previously healthy women who develop preeclampsia, diastolic and systolic left ventricular function abnormalities have been demonstrated, but these rarely develop into $\mathrm{HF}^{35}$ However, in women with pre-existing heart disease, the added strain of pre-eclampsia precipitates HF resulting in a rate as high as $30 \%$ of the patients. This is an important novel finding of our study, which indicates that patients with heart disease who develop pre-eclampsia should be monitored carefully for the development of HF. One-third of the HF associated with pre-eclampsia was in patients with peripartum cardiomyopathy, which is a known association. ${ }^{35}{ }^{36}$ However, two-thirds of the HF occurring in patients with pre-eclampsia occurred in patients with other underlying diseases. HF was also associated with endocarditis, which likely was a cause of HF. Caesarean section rates were high in patients with HF, with the majority having a CS for cardiac reasons. Women with HF were often delivered preterm probably to shorten the period of volume load and to be able to institute more aggressive therapy for the treatment of HF, however, the decision for early delivery may have a negative impact on the offspring in the longer term. ${ }^{37}$ On the other hand, fetal death and intrauterine growth 
Table 3 Onset of HF in patients per different diagnostic group

\begin{tabular}{lccll}
\hline Type of heart disease & Number of patients & Heart failure (\%) & Timing of HF (median weeks of gestation) & IQR $^{*}$ \\
\hline Aortic abnormality & 28 & 21 & 19 & $(8-32)$ \\
Complete atrioventricular septal defect & 26 & 15 & 23 & $(3-43)$ \\
Persistent ductus artriosus & 31 & 23 & 24 & $(12-36)$ \\
Mitral stenosis & 79 & 31 & 25 & $(13-37)$ \\
Ventricular septal defect & 113 & 4.4 & 27 & $(2-48)$ \\
Atrial septal defect & 111 & 8.1 & 30 & $(9-47)$ \\
Aortic coarctation & 77 & 7.6 & 33 & $(15-44)$ \\
Hypertrophic obstructive cardiomyopathy* & 11 & 18 & 34 & $(26-40)$ \\
Aortic stenosis and regurgitation* & 19 & 11 & 34 & $(26-42)$ \\
Pulmonary valve abnormality* & 61 & 34 & 37 & $(16-69)$ \\
Dilated cardiomyopathy & 32 & 21 & 38 & $(20-48)$ \\
Mitral regurgitation & 86 & 18 & 39 & $(24-50)$ \\
Mitral stenosis and regurgitation & 63 & 3.6 & 40 & $(19-57)$ \\
Transposition of the great arteries* & 56 & 68 & 40 & $(37-40)$ \\
Peripartum cardiomyopathy/myocarditis & 17 & 31 & 41 & $(37-44)$ \\
Non obstructive hypertrophic cardiomyopathy & 16 & 4.2 & 42 & $(16-66)$ \\
Tetralogy of Fallot & 119 & 8 & $(34-48)$ \\
Ischaemic heart disease* & 25 & & $(41-42)$ \\
\hline
\end{tabular}

${ }^{*}$ Range instead of IQR.

$\mathrm{HF}$, heart failure.

retardation occurred more often in patients with HF, which may keenly illustrate the difficult balance between early delivery and prolonging pregnancy in this high-risk situation. Reassuringly, neonatal death rates were not different.

\section{Limitations}

Some of the parameters previously described in the literature were not collected in this database, such as the severity of left ventricular outflow tract obstruction (peak aortic gradient $>50 \mathrm{~mm} \mathrm{Hg}$ or aortic valve area $<1.0 \mathrm{~cm}^{2}$ ). Therefore, we could neither confirm nor contradict the value of these previously identified predictors. Echocardiographic and laboratory data (such as right ventricular systolic pressure) were not available in a majority of the patients and, therefore, could not be involved in the multivariable analysis. As with other international registries, the input and quality of data was checked in only 5-10\% of cases. Additionally, some centres had much higher volumes than others. Since our dataset had limitations, necessarily some of the definitions (such as pulmonary hypertension) deviated from current guidelines, therefore, all data and comments on this matter must be seen in this perspective. We did not collect detailed information on the severity of HF, although we do know that all patients needed treatment. Details on type of treatment and length of hospital stay could, however, not be analysed. Importantly, the use of predictors has limitations in estimating the risk of pregnancy in individual patients. Always, predictors identified in multiple studies must be taken into account together with the results of disease-specific studies. Although we showed that timing of HF was dependent on underlying heart disease, some of the subgroups were small. Consequently, our findings need to be confirmed in future large studies. As with all registries, there was some missing information, this was about $4 \%$.

\section{CONCLUSION}

HF was the most common complication in this pregnancy registry. Timing of HF was dependant on the underlying cardiac diagnosis, with $\mathrm{HF}$ in the second trimester occurring mainly in patients with shunt lesions or VHD. By contrast, patients with cardiomyopathy and IHD developed HF shortly after delivery. In addition to the previously recognised risk factors such as prepregnancy signs of HF, high NYHA class or WHO category $\geq 3$, we discovered new predictors for HF: cardiomyopathy or
Figure 2 Occurrence of heart failure in patients with structural heart or ischaemic heart disease during and after pregnancy. Y-axis: Percentage of patients of total number of patients with heart failure. X-axis: In red, weeks of gestation; in dark blue, heart failure at the first day after delivery; and in light blue, heart failure in the weeks postpartum. Above the bars, the number of patients still pregnant at the beginning of the period is displayed.

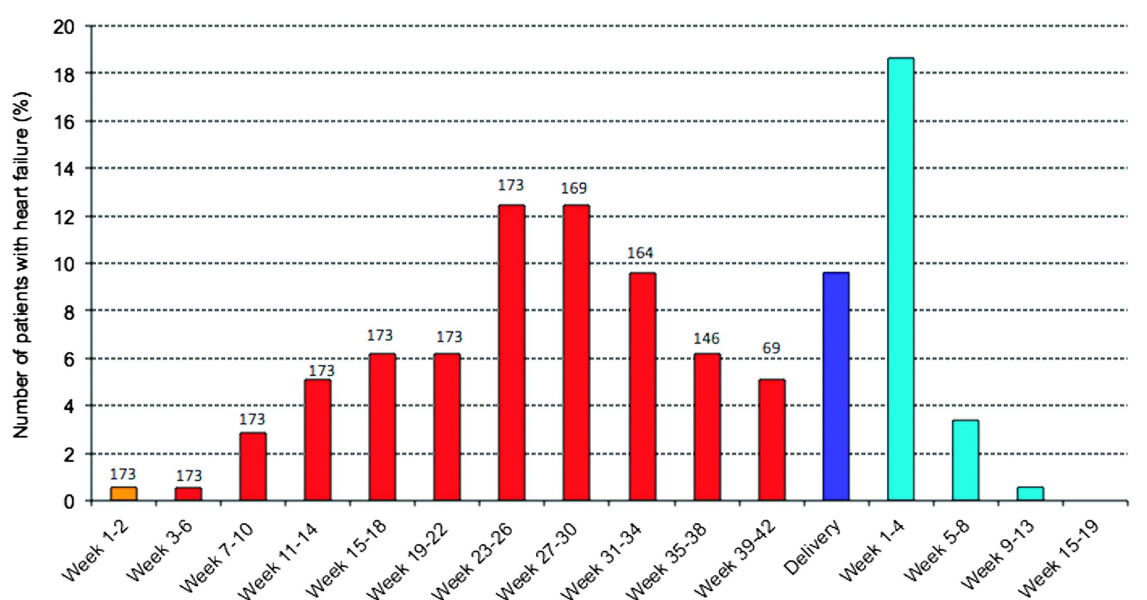


Table 4 Other complications during pregnancy and fetal outcome in patients with and without $\mathrm{HF}$

\begin{tabular}{|c|c|c|c|c|}
\hline & $\begin{array}{l}\text { Total } \\
\text { group } \\
n=1321\end{array}$ & $\begin{array}{l}\text { Patients } \\
\text { with HF } \\
(n=173)\end{array}$ & $\begin{array}{l}\text { Patients } \\
\text { without HF } \\
\text { ( } n=1148)\end{array}$ & p Value \\
\hline $\begin{array}{l}\text { Maternal mortality } \\
(\%)\end{array}$ & 1 & 4.8 & 0.5 & $<0.001$ \\
\hline \multicolumn{5}{|l|}{ Cardiac (\%) } \\
\hline Atrial fibrillation & 0.9 & 1.2 & 0.9 & 0.71 \\
\hline $\begin{array}{l}\text { Ventricular } \\
\text { arrhythmias }\end{array}$ & 2 & 2.9 & 1.8 & 0.35 \\
\hline $\begin{array}{l}\text { Thromboembolic } \\
\text { events }\end{array}$ & 0.5 & 1.2 & 0.3 & 0.14 \\
\hline Endocarditis & 0.2 & 1.2 & 0.1 & 0.006 \\
\hline $\begin{array}{l}\text { Bleeding } \\
\text { complications } \\
\text { postpartum }\end{array}$ & 4.9 & 4.6 & 5 & 0.85 \\
\hline \multicolumn{5}{|l|}{ Obstetric (\%) } \\
\hline $\begin{array}{l}\text { Intra uterine growth } \\
\text { retardation }\end{array}$ & 5.8 & 13 & 4.6 & $<0.001$ \\
\hline $\begin{array}{l}\text { Pregnancy induced } \\
\text { hypertension }\end{array}$ & 2.4 & 2.9 & 2.4 & 0.67 \\
\hline (Pre-)eclampsia & 3.3 & 12 & 1.9 & $<0.001$ \\
\hline $\begin{array}{l}\text { Bleeding } \\
\text { complications } \\
\text { during pregnancy }\end{array}$ & 1.6 & 2.9 & 1.4 & 0.14 \\
\hline \multicolumn{5}{|l|}{ Fetal outcome (\%) } \\
\hline Fetal death & 1.7 & 4.6 & 1.2 & 0.001 \\
\hline Neonatal death & 0.6 & 0.7 & 0.6 & 0.92 \\
\hline $\begin{array}{l}\text { Premature birth } \\
<37 \text { weeks }\end{array}$ & 15 & $30-$ & 13 & $<0.001$ \\
\hline $\begin{array}{l}\text { Birth weight } \\
<2500 \mathrm{~g}\end{array}$ & 14 & 24 & 13 & $<0.001$ \\
\hline Apgar score $<7(\%)$ & 10 & 13 & 9.3 & 0.10 \\
\hline $\begin{array}{l}\text { Adjusted mean } \\
\text { birth weight }(\mathrm{g})^{*}\end{array}$ & & 3328 & 3358 & 0.46 \\
\hline
\end{tabular}

pulmonary hypertension. Furthermore pre-eclampsia during pregnancy was associated with $\mathrm{HF}$, and patients with $\mathrm{HF}$ were delivered preterm more frequently.

\section{Key messages}

\section{What is already known about this subject}

Heart failure is one of the most important complications in pregnant women with heart disease, causing maternal and fetal mortality and morbidity.

\section{What this study adds}

Heart failure was the most common complication in pregnant women with underlying heart disease. Women with signs of heart failure prior to pregnancy, NYHA $\geq 3$, WHO $\geq 3$, cardiomyopathy or pulmonary hypertension are especially at risk. In our study, there appeared to be two peaks for onset of heart failure: the first peak at the end of the second and beginning of the third trimester, and the second peak around delivery. Women with heart disease who develop pre-eclampsia, have a risk of $30 \%$ to develop heart failure during their pregnancy.
Acknowledgements The investigators participating in the ROPAC at 1 June 2011 are listed in the online supplementary appendix. The ROPAC is included in the EurObservational Research Programme (EORP) of the European Society of

Cardiology. The EurObservational Research Programme (EORP) was sponsored by the following companies: Abbott Vascular Int., Amgen, Bayer Pharma, Bristol Myers Squibb, Boehringer Ingelheim, Boston Scientific Int., Daiichi Sankyo, Menarini Int., Merck \& Co. (MSD), Novartis, Pfizer, Servier Int. If you are interested in joining this registry, please go to the following website: (http://www.escardio.org/ guidelines-surveys/eorp/surveys/pregnancy/Pages/welcome.aspx). We thank the EORP team for their excellent support: Elin Folkesson Lefrancq, Cecile Laroche, Charles Taylor, Gerard Gracia, Viviane Missiamenou, Marème Konte, Maryna Andarala, Emanuela Fiorucci, Patti-Ann McNeill, Myriam Glémot and Malika Manini.

Contributors All authors have made significant contributions to the design, execution, analysis and writing of this study, and will share responsibility for the published material.

\section{Competing interests None.}

Ethics approval When warranted, ethical approval or Institutional Review Board was obtained (eg, Germany, USA, Canada, Belgium), however, in many countries the procedure to obtain ethical approval was waived because of the anonymised and untraceable nature of the data.

Provenance and peer review Not commissioned; externally peer reviewed.

\section{REFERENCES}

1 Garovic VD, Bailey KR, Boerwinkle E, et al. Hypertension in pregnancy as a risk factor for cardiovascular disease later in life. J Hypertens 2010;28:826-33.

2 Hunter S, Robson SC. Adaptation of the maternal heart in pregnancy. Br Heart J 1992:68:540-3

3 Siu SC, Sermer M, Colman JM, et al. Prospective multicenter study of pregnancy outcomes in women with heart disease. Circulation 2001;104:515-21.

4 Drenthen W, Boersma E, Balci A, et al. Predictors of pregnancy complications in women with congenital heart disease. Eur Heart J 2010;17:2124-32.

5 Khairy P, Ouyang DW, Fernandes SM, et al. Pregnancy outcomes in women with congenital heart disease. Circulation 2006;113:517-24.

6 Regitz-Zagrosek V, Blomstrom Lundqvist C, Borghi C, et al. ESC Guidelines on the management of cardiovascular diseases during pregnancy: the Task Force on the Management of Cardiovascular Diseases during Pregnancy of the European Society of Cardiology (ESC). Eur Heart J 2011;32:3147-97.

7 Sliwa K, Hilfiker-Kleiner D, Petrie MC, et al. Current state of knowledge on aetiology, diagnosis, management, and therapy of peripartum cardiomyopathy: a position statement from the Heart Failure Association of the European Society of Cardiology Working Group on peripartum cardiomyopathy. Eur I Heart Fail 2010;12:767-78.

8 Elkayam U, Bitar F. Valvular heart disease and pregnancy part I: native valves. J Am Coll Cardiol 2005:46:223-30

9 Hameed A, Karaalp IS, Tummala PP, et al. The effect of valvular heart disease on maternal and fetal outcome of pregnancy. J Am Coll Cardiol 2001;37:893-9.

10 Silversides CK, Colman JM, Sermer M, et al. Cardiac risk in pregnant women with rheumatic mitral stenosis. Am J Cardiol 2003;91:1382-5.

11 Hunter $\mathrm{S}$, Robson $\mathrm{S}$. Adaptation of the maternal heart in pregnancy. Br Heart J 1992:68:540-3.

12 Robson SC, Dunlop W, Boys RJ, et al. Cardiac output during labour. Br Med J 1987:295:1169-72.

13 Karamermer Y, Roos-Hesslink JW. Pregnancy and adult congenital heart disease Expert Rev Cardiovasc Therap 2007:5:859-69.

14 Hatton R, Colman JM, Sermer M, et al. Cardiac risks and management of complications in pregnant women with congenital heart disease. Future Cardiol 2012;8:315-27.

15 Drenthen W, Pieper PG, Roos-Hesselink JW, et al. Outcome of pregnancy in women with congenital heart disease: a literature review. J Am Coll Cardiol 2007:49:2303-11.

16 Krul SP, van der Smagt JJ, van den Berg MP, et al. Systematic review of pregnancy in women with inherited cardiomyopathies. Eur J Heart Fail 2011;13:584-94.

17 Grewal J, Siu SC, Ross HJ, et al. Pregnancy outcomes in women with dilated cardiomyopathy. JACC 2009;55:45-52.

18 Silversides CK, Salehian O, Oechslin E, et al. Canadian Cardiovascular Society 2009 Consensus Conference on the management of adults with congenital heart disease: complex congenital cardiac lesions. Can I Cardiol 2010;26:e98-117.

19 Roos-Hesselink JW, Ruys TP, Stein Jl, et al. Outcome of pregnancy in patients with structural or ischaemic heart disease: results of a registry of the European Society of Cardiology. Eur Heart J 2013;34:657-65.

20 Hunt SA, Abraham WT, Chin MH, et al. 2009 Focused update incorporated into the ACC AHA 2005 Guidelines for the Diagnosis and Management of Heart Failure in Adults A Report of the American College of Cardiology Foundation/American Heart Association Task Force on Practice Guidelines Developed in Collaboration With the International Society for Heart and Lung Transplantation. J Am Coll Cardiol 2009;53:e1-90. 
21 World Economic Outlook (WEO) Growth Resuming, Dangers Remain, April 2012 177-180 http://www.imf.org/external/pubs/ft/weo/2012/01/index.htm (20 April 2012).

22 Thorne S, MacGregor A, Nelson-Piercy C. Risks of contraception and pregnancy in heart disease. Heart 2006;92:1520-5

23 Warnes CA, Liberthson R, Danielson GK, et al. Task force 1: the changing profile of congenital heart disease in adult life. J Am Coll Cardiol 2001;37:1170-5.

24 Vriend JW, Drenthen W, Pieper PG, et al. Outcome of pregnancy in patients after repair of aortic coarctation. Eur Heart J 2005;26:2173-8.

25 Lesniak-Sobelga A, Tracz W, KostKiewicz M, et al. Clinical and echocardiographic assessment of pregnant women with valvular heart diseases-maternal and fetal outcome. Int I Cardiol 2004;94:15-23.

26 Yap SC, Drenthen W, Meijboom FJ, et al. Comparison of pregnancy outcomes in women with repaired versus unrepaired atrial septal defect. BJOG 2009;116:1593-601.

27 Yap SC, Drenthen W, Pieper PG, et al. Pregnancy outcome in women with repaired versus unrepaired isolated ventricular septal defect. BJOG 2010;117:683-9.

28 Canobbio MM, Morris CD, Graham TP, et al. Pregnancy outcomes after atrial repair for transposition of the great arteries. Am J Cardiol 2006;98:668-72.

29 Guedes A, Mercier LA, Leduc L, et al. Impact of pregnancy on the systemic right ventricle after a Mustard operation for transposition of the great arteries. J Am Coll Cardiol 2004;44:433-7.
30 Drenthen $\mathrm{W}$, Pieper PG, Ploeg M, et al. Risk of complications during pregnancy after Senning or Mustard (atrial) repair of complete transposition of the great arteries. Eur Heart J 2005;26:2588-95.

31 Bedard E, Dimopoulos K, Gatzoulis MA. Has there been any progress made on pregnancy outcomes among women with pulmonary arterial hypertension? Eur Heart J 2009:30:256-65.

32 Song YB, Park SW, Kim JH, et al. Outcomes of pregnancy in women with congenital heart disease: a single center experience in Korea. J Korean Med Sci 2008;23:808-13.

33 Eindhoven JA, van den Bosch AE, Jansen PR, et al. The usefulness of brain natriuretic peptide in complex congenital heart disease: a systematic review. J Am Coll Cardiol 2012;60:2140-9.

34 Tanous D, Siu SC, Mason J, et al. B-type natriuretic peptide in pregnant women with heart disease. J Am Coll Cardiol 2010;56:1247-53.

35 Melchiorre K, Thilaganathan B. Maternal cardiac function in pre-eclampsia. Curr Opinion Obst Gynecol 2011;23:440-7.

36 Elkayam U. Clinical characteristics of peripartum cardiomyopathy in the United States: diagnosis, prognosis, and management. J Am Coll Cardiol 2011;58: 659-70.

37 Gibson AT, Carney S, Cavazzoni E, et al. Neonatal and postnatal growth. Horm Res 2000;53(Suppl 1):42-9. 